IJBPAS, November, 2021, 10(11): 4109-4116

ISSN: $2277-4998$

International Journal of Biology, Pharmacy and Allied Sciences (IJBPAS)

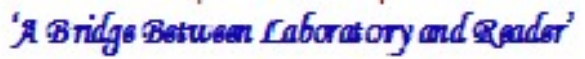

www.ibpas,com

INHIBITORY PROPERTY OF BARLERIA CRISTATA EXTRACT ON A-AMYLASE AND A-GLUCOSIDASE KEY IN DIABETES AND ANTIOXIDANT

\title{
VASANTH $\mathrm{S}^{1^{*} \text {, SIVA VIJAYAKUMAR T }}{ }^{2}$, JASMINE BUELAH. J ${ }^{1}$ AND MEENAKUMARI $\mathbf{K}^{1}$
}

1: Research \& Development Wing, Sree Balaji Medical College \& Hospital, BIHER, Chrompet, Chennai- 600044

2: Assistant Professor, Department of Biotechnology, Srimad Aandavan Arts \& Science College, Tiruvanaikovil

*Corresponding Author: Dr. S. Vasanth: E Mail: sakthivel.vasanth@gmail.com

Received 22 ${ }^{\text {nd }}$ Feb. 2021; Revised 20 ${ }^{\text {th }}$ April 2021; Accepted $6^{\text {th }}$ May 2021; Available online $1^{\text {st }}$ Nov. 2021

https://doi.org/10.31032/IJBPAS/2021/10.11.5733

\begin{abstract}
Objectives: To study the in vitro anti-diabetic and antioxidant activity of Barleria cristata in two extracts hexane and chloroform. Material and Methods: hexane and chloroform extract of leaf of Barleria cristata was tested for their anti-diabetic activity. The in vitro anti-diabetic activity from $\alpha$-amylase, $\alpha$-glucosidase and antioxidant activity was used to assess the potential activity of the fractions. Results: Our attempt results suggest that hexane and chloroform leaf extract from Barleria cristata show signs of dose-dependent increases to inhibitory activity on $\alpha$ amylase, $\alpha$-glucosidase enzymes and antioxidant activity when compared with control. Hexane leaves to extract produced maximum in-vitro anti-diabetic effect and antioxidant activity when compared to chloroform extract. Conclusion: The Hexane leaf extract from Barleria cristata may be used in managing of blood glucose in medical condition like diabetes.
\end{abstract}

Keywords: Barleria cristata; hexane extract; chloroform extract; anti-diabetic activity; antioxidant activity; in vitro study 


\section{INTRODUCTION}

Diabetes mellitus (DM) is a metabolic deficiency characterized by failure of glucose homeostasis, is characterized by hypoglycemia, lipidemia and oxidative stress affected by many individuals to longstanding complications [1]. In modern world, natural medicines have been brought a huge feasible in herbal medicine with plenty of curative potential to cure many communicable diseases without associated with the side effects not like artificial drugs. A challenge to investigate herbal medicine which may useful in the impediment of diabetes and antioxidant possible by the hexane and chloroform extracts of Barleria cristata leaves belongs to the family of acanthaceae. Barleria cristata have historically been used to treat a wide range of illnesses, including antimicrobial, antioxidant, hepatoprotective, antidiabetic and anti- inflammatory activity, $[1,2,3]$.

The Barleria cristata plant contains alkaloids, flavonoid kind rich in phenolic compounds, in particular apigenin, quercetin, naringenin, luteolin and apigenin glucuronide. Recently reported in rats that nontoxic naringenin in high dose could avoid the glucose absorption from the intestine [4]. Leaf, stem and roots of Barleria species have more widely used against diabetes and respiratory diseases $[5,3]$. In light of this, the admirable things of species belonging to the same genus, in the aim of the present study was to screen the phytochemical, evaluate radical scavenging and antidiabetic properties of Barleria cristata leaf in two different extracts hexane and chloroform.

\section{MATERIALS AND METHODS}

\section{Collection of Plant Material}

Fresh leaves of healthy Barleria cristata Linn after authenticated by Prof. P. Jayaraman, PARC, Chennai. The voucher specimen was given the No. PARC/2016/3326/1. The fresh leaves were used for the study was obtained from Kurumberi, Vellore district, Tamilnadu, India.

\section{Preparation of leaves Extract}

The leaves was washed with running tap water, Shadow dried and powdered well using a mixer and stored future use. $100 \mathrm{~g}$ powdered of was taken and subjected to successive solvent extraction $(500 \mathrm{ml})$ with to hexane and chloroform. The plant extracts were concentrated and stored in an airtight vial for further studies.

\section{Preliminary Phytochemical Screening}

Test for the presence of phytoconstituents such as alkaloids, carbohydrates, flavonides, saponin, steroids, 
tannins and phenolic compounds were studied using standard phytochemicals procedures [6].

\section{Antioxidant activity}

DPPH Free radical scavenging activity

Hexane and chloroform extract of Barleria cristata at different concentrations $(20-100 \mu \mathrm{g})$ were taken $(0.4 \mathrm{ml})$ and mix with $1.0 \mathrm{ml}$ of $0.2 \mathrm{~mm}$ DPPH solution, resulting in the absolute concentration of DPPH being $0.1 \mathrm{~mm}$. The mixture was shaken well and left to place for $30 \mathrm{~min}$, and the absorbance was measured at 517nm [7]. The DPPH Free radical scavenging activity was compared with BHT.

\section{Ferric reducing antioxidant power (FRAP)}

The FRAP was determined according to the method of Oyaizu. ${ }^{[8]}$ Briefly, various concentrations of extracts $(20-100 \mu \mathrm{g})$ in 1 $\mathrm{ml}$ of distilled water were mixed with 2.5 of $\mathrm{ml} 0.2 \mathrm{M}$ phosphate buffer $(\mathrm{pH} 6.6)$ and 1 \%potassium ferricyanide $(2.5 \mathrm{ml})$. The mixture was incubated at $50^{\circ} \mathrm{C}$ for $25 \mathrm{~min}$. An aliquot $(2.5 \mathrm{ml})$ of trichloroacetic acid $(10 \%)$ was added to the mixture, the mixture was then centrifuged at 3000 RPM for 10 min. The supernatant $(2.5 \mathrm{ml})$ was mixed with distilled water $(2.5 \mathrm{ml})$ and $\mathrm{FeCl} 3(0.5$ $\mathrm{ml}, 0.1 \%$ ) and the absorbance was measured at $700 \mathrm{~nm}$. Ascorbic acid was used as the reference. The increased absorbance of the reaction mixture indicated increased reducing power.

\section{In vitro anti-diabetic studies}

\section{Inhibition of $\alpha$ - amylase enzyme}

The inhibition alpha-amylase enzyme was determined by Malik and Singh. [9] Briefly, the total assay mixture containing $200 \mu$ of sodium phosphate buffers $(0.02 \mathrm{M})$, $20 \mu \mathrm{l}$ of enzyme, and the plant extracts from the range of $20-100 \mu 1$ were incubated for 10 mins at room temperature followed by the addition of $200 \mu \mathrm{l}$ of $1 \%$ starch in all the test tubes. Both control and plant extracts were added with starch solution and left to react with alpha- amylase solution to alkaline environment at $25^{\circ} \mathrm{C}$. The changes in reaction were measured more than 3 minutes. The production of maltose was quantified at $540 \mathrm{~nm}$.

\section{Inhibition of $\alpha$ - glucosidase enzyme}

The inhibition of alpha-glucosidase enzyme activity was determined [10]. Incubating a solution to starch substrate (2\% w/v maltose) $1 \mathrm{ml}$ with $0.2 \mathrm{M}$ Tris buffer $\mathrm{pH}$ 8.0 and different concentration $(20-100 \mu 1)$ of plant extract was added incubation for $5 \mathrm{~min}$ at $37^{\circ} \mathrm{C}$. The reaction was initiated by adding $1 \mathrm{ml}$ of alpha-glucosidase enzyme $(1 \mathrm{U} / \mathrm{ml})$ to it followed by incubation for $40 \mathrm{mins}$ at $35^{\circ} \mathrm{C}$. Then the reaction was terminated by the 
addition of $2 \mathrm{ml}$ of $6 \mathrm{~N} \mathrm{HCl}$. Then the color development was measured at 540nm.

\section{RESULT}

\section{Phytochemical screening}

Table 1 shown the phytoconstituents of Barleria cristata, which shows that the alkaloids, carbohydrates, glycosides, steroids, flavanoid, saponins and phenolic compounds are present in different extracts of the leaf. The percentage yield of hexane and chloroform extracts of Barleria cristata Leaves $7.5 \% \& 9.0 \%$. In that maximum yield was found in chloroform extract.

\section{Antioxidant activity}

DPPH radicals have been used to test the free radical activities of hexane and chloroform extracts. All the samples were analyzed in triplicate. The antioxidant activity of the extracts was estimated by DPPH free radical scavenging, using butylated hydroxytoluene (BHT) as controls were shown (Table 2).

The hexane extract ensured the strongest free radical-scavenging activity with concentration value of $68.6 \mu \mathrm{g} / \mathrm{mL}$ (Table 2). On the other hand the lowest capacity to reduce DPPH was observed in Barleria cristata chloroform extract $.22 .3 \mu \mathrm{g} / \mathrm{mL}$.

The reducing power of hexane and chloroform extracts of Barleria cristata Leaves, and the standard ascorbic acid at concentrations is shown Table 3. A significant $(\mathrm{p}<0.05)$ dose response relationship is found in the Ferric Reducing Power activity in Barleria cristata extract.

Hence the result visibly indicates that the reducing power of the Barleria cristata extract increased to increasing the concentration and is comparable with the standard ascorbic acid, hence Barleria cristata is having the antioxidant activity.

\section{In vitro $\alpha$ - Amylase Inhibitory Activity}

Polysaccharides are breakdown into simple sugar by the action of enzyme $\alpha$ Amylase and only monosugar are absorbed in the stomach form food. Barleria cristata leave extracts (Hexane \& Chloroform) were shows the dose-dependent increases from percentage inhibitory activity. Hexane extract from Barleria cristata showed a maximum percentage inhibition $60.7 \%$ at a concentration of $100 \mu 1$ while its chloroform extract shows $58.3 \%$ (Table 4).

\section{In vitro $\alpha$ - Glucosidase Inhibitory Activity}

The dose-dependent $\alpha$-glucosidase inhibitory activities were indicated in Table 5. The hexane and chloroform extracts tested showed a concentration-dependent inhibitory activity with a similar progress profile using graded concentrations. The Barleria cristata leave extracts revealed a significant inhibitory action of alpha-glucosidase enzyme. The percentage inhibition varied 


\section{from $41.4 \%-17.3 \%$ for the highest (Table 5).}

concentration on the lowest concentration

Table 1: Preliminary Phytochemical Screening of Barleria Cristata

\begin{tabular}{|c|c|c|c|}
\hline S. No. & Phytochemical Constituents & Hexane Extract & Chloroform Extract \\
\hline $\mathbf{1}$ & Alkaloids & + & + \\
\hline $\mathbf{2}$ & Carbohydrates & + & + \\
\hline 3 & Flavonoids & + & + \\
\hline 4 & Saponin & + & - \\
\hline $\mathbf{5}$ & Steroids & - & + \\
\hline 6 & Tannins & + & + \\
\hline 7 & Phenolic compounds & + & \\
\hline
\end{tabular}

Table 2: DPPH free radical scavenging activity of Barleria cristata extracts

\begin{tabular}{|c|c|c|c|c|}
\hline \multirow[t]{2}{*}{ S. No } & \multirow{2}{*}{$\begin{array}{l}\text { Concentration of } \\
\text { Sample }(\mu \mathrm{l})\end{array}$} & \multicolumn{2}{|c|}{$\%$ of Inhibition } & \multirow[t]{2}{*}{ Control \% BHT } \\
\hline & & $\begin{array}{l}\text { Hexane } \\
\text { Extract }\end{array}$ & $\begin{array}{c}\text { Chloroform } \\
\text { Extract } \\
\end{array}$ & \\
\hline 1 & 20 & 25.9 & 22.3 & \multirow{5}{*}{91.8} \\
\hline 2 & 40 & 37.2 & 29.6 & \\
\hline 3 & 60 & 45.5 & 35.1 & \\
\hline 4 & 80 & 59.7 & 50.8 & \\
\hline 5 & 100 & 68.6 & 59.7 & \\
\hline
\end{tabular}

Values are given in Mean \pm SEM

Table 3: Ferric reducing antioxidant power activity of Barleria cristata extracts

\begin{tabular}{|c|c|c|c|c|}
\hline \multirow[t]{2}{*}{ S. No } & \multirow{2}{*}{$\begin{array}{l}\text { Concentration of } \\
\text { Sample }(\mu \mathrm{l})\end{array}$} & \multicolumn{2}{|c|}{$\%$ of Inhibition } & \multirow[t]{2}{*}{ Control \% Ascorbic acid } \\
\hline & & Hexane Extract & Chloroform Extract & \\
\hline 1 & 20 & 0.051 & 0.47 & \multirow{5}{*}{0.197} \\
\hline 2 & 40 & 0.068 & 0.053 & \\
\hline 3 & 60 & 0.081 & 0.070 & \\
\hline 4 & 80 & 0.095 & 0.086 & \\
\hline 5 & 100 & 0.138 & 0.129 & \\
\hline
\end{tabular}

Values are given in mean \pm SEM

Table 4: In vitro Anti-Diabetic Activity of Alpha-Amylase

\begin{tabular}{|c|c|c|c|}
\hline S. No & Sample concentration in $\mu$ I & \multicolumn{2}{|c|}{ Inhibition \% } \\
\cline { 3 - 4 } & & Hexane Extract & Chloroform Extract \\
\hline 1 & 20 & 27.5 & 21.4 \\
\hline 2 & 40 & 32.9 & 36.6 \\
\hline 3 & 60 & 41.3 & 41.9 \\
\hline 4 & 80 & 54.1 & 49.7 \\
\hline 5 & 100 & 60.7 & 58.3 \\
\hline
\end{tabular}

Values are given in Mean \pm SEM

Table 5: In vitro Anti-Diabetic Activity of Alpha Glucosidase

\begin{tabular}{|c|c|c|c|}
\hline S. No & Sample concentration in $\mu \mathrm{l}$ & \multicolumn{2}{|c|}{ Inhibition \% } \\
\cline { 3 - 4 } & & Hexane Extract & Chloroform Extract \\
\hline 1 & 20 & 21.8 & 17.3 \\
\hline 2 & 40 & 25.1 & 24.8 \\
\hline 3 & 60 & 30.5 & 29.7 \\
\hline 4 & 80 & 36.2 & 33.0 \\
\hline 5 & 100 & 41.4 & 38.1 \\
\hline
\end{tabular}

Values are given in Mean \pm SEM 


\section{DISSCUSION}

An important target for the treatment of diabetes includes the development of inhibitors of nutrient digestion and absorption. Inhibition of $\alpha$-Glucosidase and the associated reduction of glucose absorption is an attractive approach for the discovery of potent agents. In the present study has been accompanied to assess the primary phytochemical examination and the potential for Hexane and Chloroform extract from $B$. cristata leaf in inhibiting alphaglucosidase and alpha-amylase. The Hexane and Chloroform extract extracts from $B$. cristata were tested for phytochemical constituents such as flavonoid, glycosides, carbohydrates, steroids, proteins, and amino acids. Understanding the chemical components of plants assists in the identification of biological activity.

The extracts of $B$. cristata leaves contain secondary metabolites such as flavonoid, phenol, and tannins, suggesting that they have a wide range of biological activities such as anti-inflammatory, antioxidant, antiarthritic, antidiabetic, and membrane stabilising properties. This research supports previous research [3]. The presence of secondary metabolites suggests the plant's curative ability, as all of the major groups of compounds are described along with their anticancer,

anti-inflammatory,

and

antirheumatic properties [11-13].

B. cristata can effectively inhibit both alphaamylase and alpha-glucosidase enzymes in vitro in a dose-dependent manner, according to the current findings. In a model of alloxaninduced diabetes in rats, ethanol extracts from $B$. cristata seeds had a dose-dependent inhibitory effect on alpha-amylase function, resulting in a substantial decrease in blood glucose levels [14]. The alpha-amylase and alpha-glucosidase inhibitory activity of $B$. cristata can also be linked to its anti-diabetic properties. In addition, it is important to decide if $B$. cristata possesses antidiabetic potential in vivo in order to validate the plant's proven argument.

\section{CONCLUSION}

The existence of flavonoids, phenols, and terpenoids was discovered in preliminary phytochemical studies of Barleria cristata using hexane and chloroform extracts. The presence of flavonoids and phenols in the extract can serve as a foundation for scavenging active oxygen species. The observed results concluded that hexane and chloroform extracts of Barleria cristata leaves not only possess remarkable inhibitory ability against -glucosidase and -amylase, but also exhibited admirable scavenging activity on the DPPH and FRAP activity. The results 
of this study direct further study to assess the curative potentialities of Barleria cristata L. in in vivo models.

\section{ACKNOWLEDGMENTS}

The authors are thankful to Sree Balaji Medical College \& Hospital, Chrompet, Chennai-600044, Tamil Nadu, India for the facilities to carry out the research. The authors wish to record their thanks to Prof. P. Jayaraman Director, Retd, Professor, Presidency College, Chennai for authenticated of plant material.

\section{AUTHOR CONTRIBUTION}

The first author carried out the experiment. First author wrote the manuscript with support from other authors.

\section{FINANCIAL SUPPORT \\ SPONSORSHIP}

AND

Nil.

\section{CONFLICTS OF INTEREST}

We declare that we have no conflict of interest.

\section{REFERENCE}

[1] Sharma N, Vijayvergia R. A Review on Digera muricata (L.) Mart-a great versatile medicinal plant. Int. J. Pharm. Sci. Rev. Res. 2013 May; 20(1): 114-9.

[2] Gambhire M, Juvekar M, Juvekar A, Wankhede S, Sakat S. Evaluation of anti-inflammatory and radical scavenging activity of an aqueous extract of Barleria cristata leaves. Planta Medica. 2009 Jul; 75(09): PJ166.

[3] Amutha $\mathrm{K}$, Doss $\mathrm{D}$. In vitro Antioxidant Activity of Ethanolic Extract of Barleria cristata L. Leaves. Res. J. Pharmacogn. Phytochem. 2009; 1(3): 209-12.

[4] Vasanth, S., Bupesh, G., Siva Vijayakumar, T., Balachandar, V., Gunasekaran, D. R. Evaluation of In vitro Antidiabetic and Antioxidant Potential of Barleria cristata Leaves Extracts. Asian J Pharm Clin Res, 2018; 11(4): 287-290.

[5] Hemalatha K, Hareeka N, Sunitha D. Chemical constituents isolated from leaves of Barleria cristata Linn. Int J Pharma Bio Sci. 2012; 3(1).

[6] Ortiz-Andrade, R. R., et al. Antidiabetic and toxicological evaluations of naringenin in normoglycaemic and NIDDM rat models and its implications on extra-pancreatic glucose regulation. Diabetes, Obesity and Metabolism. 2008 Nov; 10(11): 1097-104..

[7] Evans WC, Evans T. Pharmacognosy, 5th Edn., Cambridge University Press, London 2003; 336-93. 
[8] Braca, Alessandra, et al. "Antioxidant principles from bauhinia tarapotensis." J. Nat. Prod. 64.7 (2001): 892-895.

[9] Oyaizu, M. "Studies on products of browning reaction. Antioxidant activities of products of browning reaction prepared from glucoamine." Jap. J. Nutri 986.44: 307-315.

[10] Malick, C. P., and M. B. Singh. "Plant Enzymology and Histo Enzymology Kalyari" Publishers New Delhi pp, 286." (1980).

[11] Krishnaveni, S., Theymoli Balasubramanian, and S. Sadasivam. "Sugar distribution in sweet stalk sorghum." Food chemistry 15.3 (1984): 229-232.

[12] Jyothi, K. S., and M. Seshagiri. "Invitro activity of saponins of Bauhinia purpurea, Madhuca longifolia, Celastrus paniculatus and Semecarpus anacardium on selected oral pathogens." Journal of Dentistry (Tehran, Iran) 9.4 (2012): 216.

[13] Kumar, Shashank, and Abhay K. Pandey. "Chemistry and biological activities of flavonoids: an overview." The scientific world journal 2013 (2013).
[14] Atif, Mohammed, et al. "Anticataract Potential of Barleria prionitis: In vivo Study."2014; 72: 100-5. Singh, Ranjit, P. H. Rajasree, and C. Sankar. "Screening for antidiabetic activity of the ethanolic extract of Bryonia alba roots." Int J Pharm Biol Sci 2.3 (2012): 210-5. s. 